\title{
Measurement of core temperature through semi-transparent polyamide 6 using scanner-integrated pyrometer in laser welding
}

\author{
Anton Schmailzl ${ }^{\mathrm{a}, *}$, Johannes Käsbauer ${ }^{\mathrm{a}}$, Jiří Martan ${ }^{\mathrm{b}}$, Petra Honnerová ${ }^{\mathrm{b}}$, Felix Schäfer ${ }^{\mathrm{a}}$, Maximilan Fichtl ${ }^{\mathrm{a}}$, \\ Tobias Lehrer $^{\mathrm{a}}$, Jiří Tesař ${ }^{\mathrm{b}}$, Milan Honner ${ }^{\mathrm{b}}$, Stefan Hierl ${ }^{\mathrm{a}}$ \\ a Ostbayerische Technische Hochschule Regensburg, Galgenbergstraße 30, 93053 Regensburg, Germany \\ ${ }^{\mathrm{b}}$ New Technologies Research Centre (NTC), University of West Bohemia, Univerzitni 8, 30100 Plzen, Czech Republic
}

\section{A R T I C L E I N F O}

\section{Article history:}

Received 5 July 2019

Received in revised form 28 September 2019

Accepted 29 September 2019

\section{Keywords:}

Semi-transparent polymer

Pyrometer

Laser transmission welding

Temperature measurement

\begin{abstract}
A B S T R A C T
Predicting the core temperature during welding is an ambitious aim in many research works. In this work, a 3D-scanner with integrated pyrometer is characterized and used to measure the temperature during quasi-simultaneous laser transmission welding of polyamide 6 . However, due to welding in an overlap configuration, the heat radiation emitted from the joining zone of a laser transmission weld has to pass through the upper polymer, which is itself a semi-transparent emitter. Therefore, the spectral filtering of the heat radiation in the upper polymer is taken into account by calibrating the pyrometer for the measurement task. Thermal process simulations are performed to compare the temperature field with the measured temperature signal. The absorption coefficients of the polymers are measured, in order to get precise results from the computation. The temperature signals during welding are in good agreement with the computed mean temperature inside the detection spot, located in the joining area. This is also true for varying laser power, laser beam diameter and the carbon black content in the lower polymer. Both, the computed mean temperature and the temperature signal are representing the core temperature. In order to evaluate the spatial sensitivity of the measurement system, the emitted heat radiation from both polymers is calculated on basis of the computed temperature field. Hereby it is found, that more than 90 percent of the detected heat radiation comes from the joining area, which is a crucial information for contact-free temperature measurement tasks on semi-transparent polymers.
\end{abstract}

(c) 2019 Elsevier Ltd. All rights reserved.

\section{Introduction}

In general, plastics joining processes are suffering from limited possibilities for process monitoring by thermal imaging, since surrounding plastic material often covers the weld seam. This is especially given for hot-plate, ultrasonic and friction welding as well as for laser-based processes e.g. laser based hot melting or laser transmission welding. For heat radiation measurement, the sensitivity range $\lambda=1.1 \ldots 2.3 \mu \mathrm{m}$ is to recommend, since thermoplastics are semi-transparent in this spectral range, which enables one to detect heat radiation emitted from the joining zone through a covering plastic part $[1,2]$. However, by using this spectral range, only an extraordinarily small portion of the emitted heat radiation can be measured. This is based on the spectral emittance for the given temperatures during welding, since the maximum of the heat radiation is emitted in the mid-wavelength infrared region and thus far away from the aforementioned spectral range. On top of that, the

\footnotetext{
* Corresponding author.

E-mail address: anton2.schmailzl@oth-regensburg.de (A. Schmailzl).
}

heat radiation emitted from the joining zone is attenuated due to absorption in the upper polymer [3]. Pyrometers with photodiodes, which are sensitive in the before mentioned range are to recommend, since these systems are operating at a high sampling rate and are cheap and easy to use. In contrast, one gets only a single temperature signal for a given detection spot of the pyrometer, whereby the process monitoring of a weld line is only possible by deflecting the spot.

By integrating a pyrometer into a scanner, the detection spot can be deflected easily, which makes it to a promising system for in-situ process monitoring of laser based welding processes [46]. For the laser transmission welding, it is already shown, that initial gaps between the polymers can be identified precisely on basis of the measured temperature during welding. Remaining gaps in the joining zone are a critical failure case, since this joining process is preferably used for generating hermetic weld seams e.g. for sensor housings or for fluid containers $[7,8]$. The most important requirement to meet is that the emitted heat radiation, coming from the joining zone, is high enough. 
On basis of the heat radiation, the scanner-integrated pyrometer yields a temperature, since the temperature and the measured heat radiation is linked together by a predefined calibration curve. However, the calibration curve of the manufacturer of the pyrometer is not valid anymore, due to the integration into the scanner. Especially signal attenuation by the scanner-optics needs to be taken into account as well [9]. Furthermore, the calibration is determined for measuring on a surface emitter, but here the heat radiation is emitted from the entire volume of both polymers. Precise temperature measurement on semi-transparent materials using heat radiation is in general a difficult task [10]. Additionally, the radiation is spectrally attenuated by the upper polymer, based on its spectral transparency. Moreover, the assignment of the measured heat radiation to an exact temperature and an exact location is more complicated, since the radiation is scattered on crystalline structures, additives and reinforcing fibers in the upper polymer [11]. On top of that, high spatial temperature gradients in perpendicular direction to the optical axis may occur, which in general complicates the assignment of the temperature signal to an exact location in the weld.

Despite the big challenges, the temperature in the joining zone is of great interest, especially for predesigning the process. High temperatures, which might lead to a thermal damaging of the material, can be avoided. Furthermore, an ideal joining temperature can be found, which yields to the highest possible joint strength.

In order to reach the goal of measuring the core temperature in laser transmission welding, a scanner-integrated pyrometer is characterized and calibrated for the measurement application. Hereby, the filtering of the heat radiation in the upper polymer is taken into account. The temperature signal is then measured during quasi-simultaneous laser transmission welding, where a high reproducibility of the welds is given, since the energy input can be adjusted precisely [3]. Afterwards, the measured signal is compared with temperature courses calculated in a thermal process simulation, in order to check if the measured temperature can be assigned to a spatial domain and finally to check the accuracy of the calibration for the herein used injection-molded polyamide 6 with the brand name "Ultramid B3s". In order to get precise results from the thermal process simulation, an adequate measurement procedure of the absorption coefficient is also evaluated, since this parameter is highly influencing the computed results, as shown in Acherjee et al. [12] and Hopmann et al. [13].

\section{Calibration of scanner-integrated pyrometer}

\subsection{D-Scanner with integrated pyrometer}

Fig. 1 shows a scheme of the optical path of the used 3Dscanner with an ytterbium fiber-laser and a coaxially integrated pyrometer.

The laser beam is focused by a focus shifter, aligned by a dichroic mirror and then deflected by the scanning mirrors. The polymers are irradiated in an overlap configuration in a working distance of $400 \mathrm{~mm}$ from the scanner. By using an ytterbium fiber-laser $(\lambda=1.07 \mu \mathrm{m})$, a high amount of the laser radiation is passing through the upper polymer, caused by the high transparency of the typically used thermoplastics at this wavelength [1]. In the following, the laser radiation reaches the lower polymer. Here it is absorbed very close to the interface, since this polymer is filled with carbon black. Thereby, the lower polymer is heated and melts in consequence. Due to heat conduction, the upper polymer is warmed and melts, also. The weld trajectory is scanned repetitively several times with a high feed rate, whereby the melting temperature is reached nearly simultaneously at each point along the entire weld trajectory.

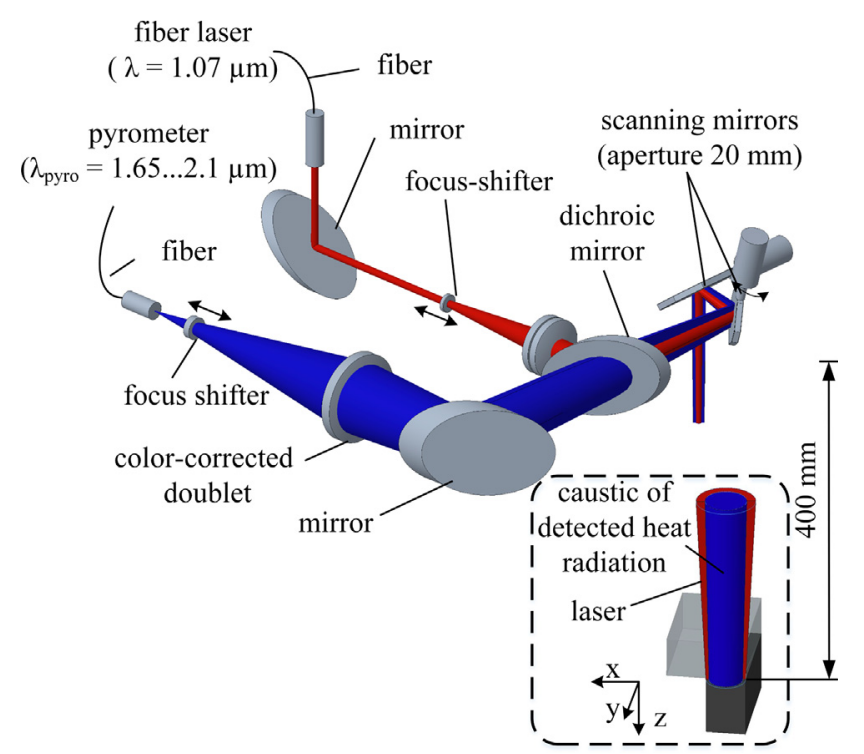

Fig. 1. 3D-Scanner with an ytterbium fiber-laser and a coaxially coupled pyrometer with an InGaAs-detector.

A small part of the heat radiation, which is hemispherical emitted from both polymers, hits the scanning mirrors. The enhanced gold coating on the scanning mirrors ensures, that the heat radiation is deflected back to the dichroic mirror. Here, the heat radiation is transmitted in the spectral range of the pyrometer $(\lambda=1.6 \ldots 2.1 \mu \mathrm{m})$ and afterwards aligned and focused into an optical fiber, which finally guides it to the pyrometer (see Fig. 1 left).

\subsection{Caustic of detected heat radiation}

The caustic of the detected heat radiation, which is represented by $90 \%$ of the totally measured heat radiation, is analyzed as proposed theoretically in Bernhard [14]. Fig. 2 (left) shows the experimental setup consisting of a black body radiator and a self-made motorized optical iris.

At first, the black body radiator is set to a predefined temperature of $350^{\circ} \mathrm{C}$ and positioned in the optical path of the pyrometer. The adjustable optical iris is placed above the black body emitter with a distance of $400 \mathrm{~mm}$ to the scanner, which is the position of the joining zone in the welding experiments. The temperature signal of the pyrometer $\left(\mathrm{T}_{\mathrm{S}}=229^{\circ} \mathrm{C}\right)$ is noted for the assumption of an emissivity coefficient of $\epsilon=1$. Here, the optical iris is fully

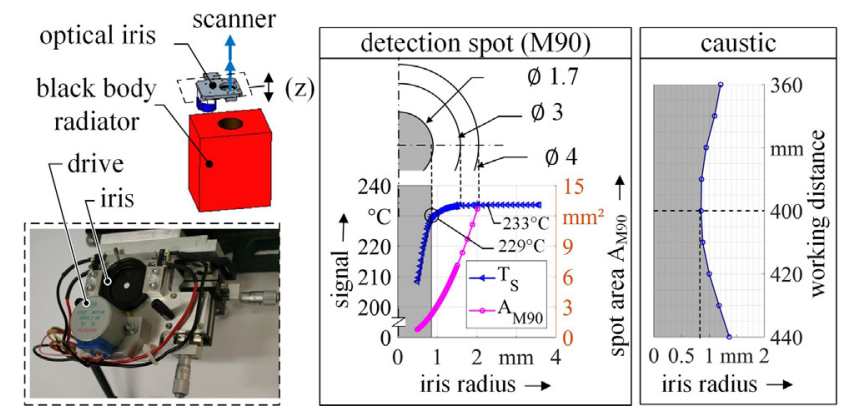

Fig. 2. Experimental setup to measure the caustic of the detected heat radiation by using a diameter-adjustable iris (left), and the results: the measured temperature in the focal position in dependence of the iris radius (middle) and the resulting caustic of the detected heat radiation, both evaluated by using an emissivity coefficient of $\epsilon=0.9$. 
opened $(\varnothing=19 \mathrm{~mm}$ ). Then, the emissivity coefficient is set to $\epsilon=0.9$, whereby the temperature signal is immediately increased. In the following, the diameter of the optical iris is reduced in steps and the temperature signal is noted again. By this, the temperature signal $\left(\mathrm{T}_{\mathrm{S}}\right)$ can be plotted over the radius of the optical iris as seen in Fig. 2 (middle). A continuous and rapid increase in the temperature signal is seen for varying the diameter of the optical iris from $\varnothing=0.5 \mathrm{~mm}$ to $\varnothing=2 \mathrm{~mm}$. No significant changes in the temperature are seen for an iris diameter greater than approximately $\varnothing=3 \mathrm{~mm}$. This means, that a change in the spot area $\left(A_{M 90}\right)$ no longer leads to a change in the temperature signal (see Fig. 2 middle).

The temperature signal for an iris diameter of $\varnothing=1.7 \mathrm{~mm}$ at a predefined emissivity coefficient of $\epsilon=0.9$ corresponds to the initially measured signal $\left(\mathrm{T}_{\mathrm{S}}=229^{\circ} \mathrm{C}\right)$, where an emissivity coefficient of $\epsilon=1$ is predefined and no iris is used (see Fig. 2 middle). At this diameter, the heat radiation received by the pyrometer is $90 \%$ of the total heat radiation received by the pyrometer. The spot diameter within $\varnothing=1.7 \mathrm{~mm}$ is referred to as the M90-spot-diameter (see Fig. 2 middle). The caustic of the detected heat radiation is obtained, by repeating the measurement procedure at different working distances (see Fig. 2 right).

The coaxial alignment between the detection spot and the laser beam is checked by measuring the centroids of two guide lasers, which are integrated in the respective optical paths. The emitted light of the guide lasers is measured with a CMOS camera. The distance between the centroids in the joining area is found to be $0.25 \pm 0.05 \mathrm{~mm}$ in $\mathrm{x}$ and $\mathrm{y}$-direction.

\subsection{Calibration}

The filtering by the upper plastic causes a reduction of the heat radiation, which is determined by measuring the temperature of a black body emitter with and without a plastic sample in the optical path. Fig. 3 shows the experimental setup (left) and the temperature signal (right) for the measurement configuration with and without a plastic sample. The emissivity coefficient is set to $\epsilon=1$ for both measurement configurations.

The initial temperature threshold of the pyrometer is $80^{\circ} \mathrm{C}$. This temperature signal is displayed by using a black body temperature of $160{ }^{\circ} \mathrm{C}$. This means, that less heat radiation is received by integrating the pyrometer into the scanner, compared to using the pyrometer as a stand-alone tool. On the one hand, the maximum numerical aperture of the pyrometer is not fully used, since the optical aperture of the scanning mirrors is limited to $\varnothing=20 \mathrm{~mm}$.
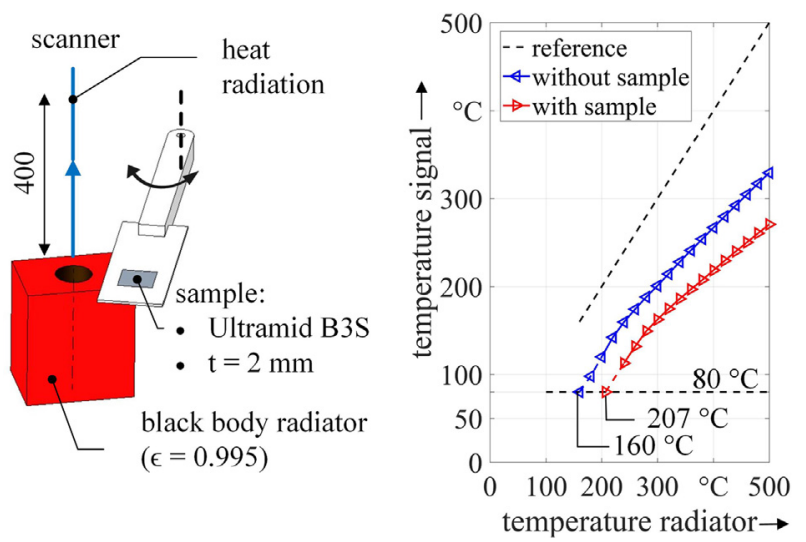

Fig. 3. Experimental setup for calibration of the scanner-integrated pyrometer by measuring the temperature of a black body radiator with and without a plastic sample inside the optical path (left) as well as the measured temperature signal plotted over the temperature of the radiator (right).
On the other hand, the heat radiation is also spectrally attenuated in the scanner, which causes losses in the received heat radiation.

The polyamide 6 sample in the optical path of the pyrometer causes a further reduction in the temperature signal. The temperature of the black body radiator $\mathrm{T}=207^{\circ} \mathrm{C}$ corresponds to the initial threshold temperature of $\mathrm{T}=80^{\circ} \mathrm{C}$ for a polyamide 6 sheet with a thickness of $2 \mathrm{~mm}$ (see Fig. 3 right). The filtering of the plastic sample causes a weakening of the temperature signal by $47^{\circ} \mathrm{C}$.

The deviation between the measured temperature signals with a polymer sheet in the optical path and without is nearly constant for the shown temperatures of the radiator (see Fig. 3 right). Obviously, the spectral emittance changes for different black body temperatures, based on Wien's law, but the filtering is not changed for the herein investigated temperature ranges. The sample is placed above the heat radiator for approximately five seconds. For this reason, an effect of warming of the samples is excluded. This is based on the observation, that the same temperature signal is seen even if the sample is positioned above the radiator for an extraordinarily long time. By using the temperature curves in Fig. 3 as calibration curves, the pyrometer can be treated as calibrated.

\subsection{Effect of carbon black content on emissivity coefficient}

Fundamentally, it has to be proven, if the emissivity coefficient of $\epsilon=1$ can also be used for measuring the temperature of the carbon black filled polymer underneath the upper polymer. By this, the temperature is measured on heated samples during cooling on ambient air. Therefore, a self-made heater with infrared filaments is used to heat up the injection-molded polyamide 6 samples with different carbon black content. Fig. 4 (left) shows the experimental setup and the measured temperature during cooling on ambient air (right).

At first, the sample with a sheet thickness of $2 \mathrm{~mm}$ is positioned in a rotatable fixture and held into the infrared heater for approximately ten seconds. Afterwards, the sample is moved into the optical path of the scanner-integrated pyrometer and the heat radiation emitted on the top side of the sample is measured by the pyrometer. Additionally, an infrared camera $(\lambda=7 \ldots 13 \mu \mathrm{m})$ measures the temperature on the bottom side, where approximately $220^{\circ} \mathrm{C}$ is displayed in the beginning of the measurement. Since the sample is extraordinarily softened due to the heating, it shows a significant deformation towards the infrared camera, even in the beginning of the measurement. Within the cooling, a further deformation but increasingly weaker is seen. This is caused by the gravity. The resulting geometry of a sample is shown in Fig. 4 (bottom left).

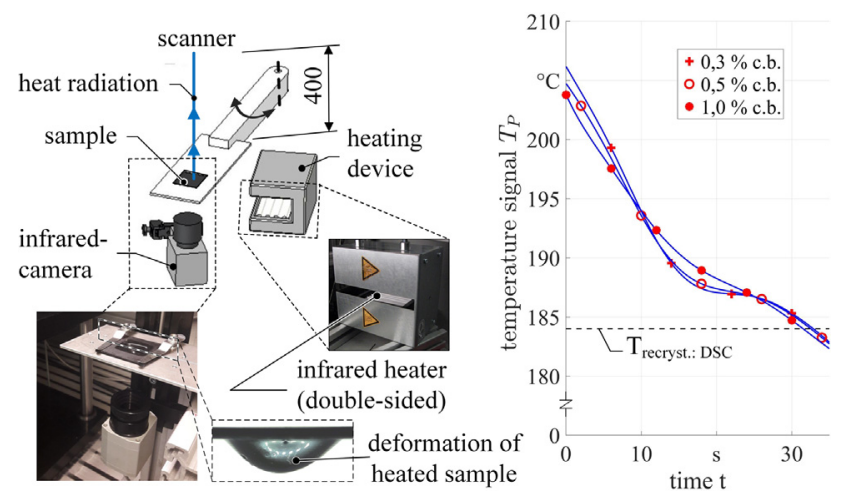

Fig. 4. Experimental setup to verify the selected emissivity coefficient of carbon black filled plastics by measuring the temperature on heated plastic samples with different carbon black contents during cooling on ambient air (left) as well as the temporal temperature course, measured by the pyrometer (right). 
The cooling on ambient air on seven samples of each carbon black content is measured. Fig. 4 (right) shows one representative temperature course of a sample with a specific each carbon black content, measured with the scanner-integrated pyrometer. A temperature plateau is seen in all temperature courses of the scanner integrated pyrometer as well as in the one of the infrared camera. This is expected, because of the phase change from liquid to solid.

The temperature signal, at which the temperature plateau is reached, is equal for seven samples at a specific carbon black content. Naturally, the recrystallization temperature of the sample is a material property, which is equal for all samples and especially independent from the start-temperature and the carbon black content.

The temperature plateaus are close to the recrystallization temperature $\left(184^{\circ} \mathrm{C}\right)$, determined in a Differential-Scanning-Calorime try (DSC) measurement (see Fig. 4 right). The small deviation between the temperature plateaus and the recrystallization temperature signalizes, that the measured temperature is very close to the real temperature, even though the emissivity coefficient is assumed to be $\epsilon=1$ for all measurements. Since the temperature signal of the plateau is nearly the same by using samples with different carbon black contents, one can state, that the emissivity of plastics is not changed significantly by changing the carbon black content between $0.3 \mathrm{wt} \%$ and $1.0 \mathrm{wt} \%$.

\section{Welding experiments with temperature measurement}

The before mentioned injection molded polyamide 6 samples with a size of $40 \times 40 \times 2 \mathrm{~mm}$ are clamped using a clamping device with a slit and irradiated in an overlap configuration, as shown in Fig. 5 (left). The laser beam is moved in y-direction along the weld trajectory with a length of $30 \mathrm{~mm}$, while the laser is on. Afterwards it is moved back to the initial starting position while the emission is switched off. This scanning procedure is repeated until a desired amount of scan repetitions is reached. The feed rate in both directions is equal.

The temperature is measured simultaneously by using the scanner-integrated pyrometer as well as an infrared camera with a spectral range of $\lambda=7 \ldots 13 \mu \mathrm{m}$ (see Fig. 5 left). The fiber-laser, the scanner and the measurement devices are integrated in a real time control system.

Since the optical path of the pyrometer is deflected simultaneously with the laser beam, the temperature is measured at different positions of the weld trajectory. The temperature signal of one weld can be assigned to a y-position for each scan repetition,

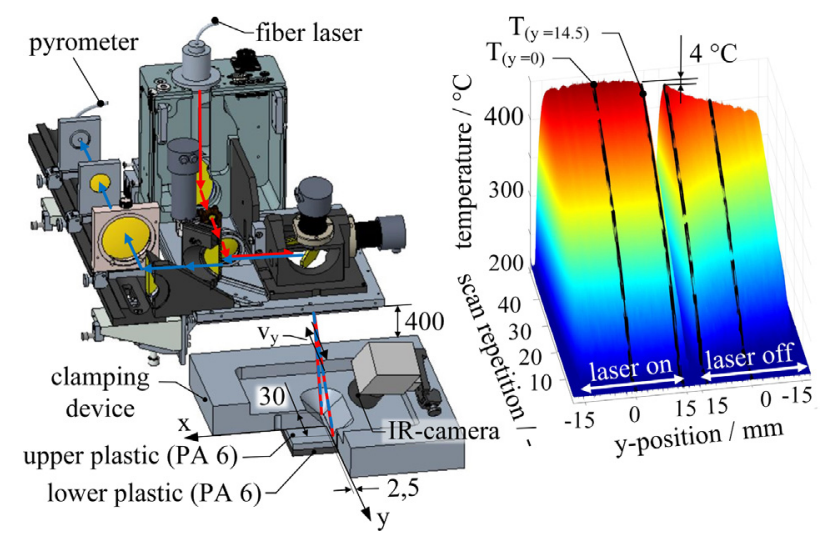

Fig. 5. Experimental setup for temperature measurement during welding of plastics in flat-flat-configuration by using the scanner-integrated pyrometer and an infrared camera (left) as well as a typical temperature signal measured with the pyrometer, plotted over y-position and scan repetition (right).
Table 1

Relevant process and material parameter.

\begin{tabular}{lll}
\hline Parameter & Symbol & Initial magnitude \\
\hline Laser power & $\mathrm{P}^{*}$ & $75 \mathrm{~W}$ \\
Laser beam diameter & $\mathrm{d}^{*}$ & $3 \mathrm{~mm}$ \\
Carbon black content & c.b.* & $1.0 \mathrm{wt} \%$ \\
Scan repetition & $\mathrm{r}^{*}$ & $50-$ \\
Feed rate & $\mathrm{v}$ & $1500 \mathrm{~mm} / \mathrm{s}$ \\
Scan frequency & $\mathrm{f}$ & $25 \mathrm{~Hz}$ \\
Clamping pressure & $\mathrm{p}$ & $1.5 \mathrm{MPa}$ \\
Sheet thickness (upper polymer) & $\mathrm{L}^{*}$ & $2 \mathrm{~mm}$ \\
Detection spot diameter & $\mathrm{d}_{\mathrm{p}}$ & $1.7 \mathrm{~mm}$ \\
& ${ }^{*}$ varied & \\
\hline
\end{tabular}

which leads to a temperature plot as shown in Fig. 5 (right). The herein used process parameters for welding are listed in Table 1.

It takes several scan repetitions until the temperature signal reaches $207^{\circ} \mathrm{C}$. One scan repetition takes $0.04 \mathrm{~s}$, in which 1200 data points are recorded by the pyrometer, which is a result of the high sampling frequency of the pyrometer $(\mathrm{f}=30 \mathrm{kHz})$. The temperature signal is nearly the same at each y-position, as far as the laser is on, whereas cooling is seen during the laser is off. The measured temperature signal at the end of the weld trajectory, e.g. $T_{(y=14.5)}$ is nearly the same while the laser is switched on and off (see Fig. 5 right). This signalizes, that reflected laser light does not influence the temperature measurement. Furthermore, one can state, that the heating occurs nearly simultaneously, which is based on the comparatively high scanning frequency $(\mathrm{f}=25 \mathrm{~Hz})$.

However, a temperature plateau is not seen. This is based on two effects: On the one hand, very fast heating and cooling occurs, whereby the time for recrystallization is very short. On the other hand, there is still a spatial temperature gradient inside the detection spot, which means, that the recrystallization-temperature is not reached simultaneously at each infinitesimal small point inside the detection spot. Thus, the measured temperature signal is the mean temperature of the material within the detection spot.

For the subsequent comparisons between measured and simulated temperatures, the temperature course in the mid-position of the weld trajectory $T_{(y=0)}$ is used (see Fig. 5 right). This allows one to analyze the effect of different process parameter settings on the temperature signal. The process parameters, laser power and laser beam diameter, are measured beforehand, in order to get accurate data for the process simulation. For this task, a beam profiler camera and a thermally based laser power meter are used.

\section{Process simulation}

\subsection{Process model}

While positioning the polymers in a flat-flat-configuration, only small deformations of the polymers are occurring during welding. Therefore, only small errors are obtained, using a thermal finite element analysis, where only the temperature based on heat conduction is computed. Heat transfer by convection and radiation is not taken into account, since it has no significant influence on the temperature in the heat affected zone, as reported by Polster [15] and Mayboudi [16]. The thermal contact conductance between the polymers is set as ideal. As the thermal conductivity and the specific heat of polymers are significantly dependent on the temperature [17], these parameters are implemented as temperature dependent values. The locally applied volumetric heat is calculated using Eq. (1), as reported in Geiger et al. [18].

$\dot{Q}=\frac{8 \cdot \alpha \cdot P}{\pi \cdot d^{2}} \cdot e^{-\alpha \cdot z-8 \cdot \frac{\left(-y_{0}-y_{y} \cdot t\right)^{2}+x^{2}}{d^{2}}}$ 
Here, $\alpha$ is the absorption coefficient of the polymer, $P$ is the laser power, $d$ is the laser beam diameter, $y_{0}$ is the start position of irradiation, $v_{y}$ is the feed rate in y-direction, $z$ is the coordinate along the optical axis and $x$ is the coordinate in perpendicular direction. Consequently, the intensity of the laser radiation is modelled using a Gaussian distribution, which approximates the intensity distribution of the fiber laser very accurately.

The absorption is modelled by using Lambert-Beer's law. The volumetric heat applied to each polymer is calculated using the respective absorption coefficient. The radiation is attenuated due to absorption in the upper polymer, which is also taken into account in the calculation of the heat input in the lower polymer. As the laser radiation at $\lambda=1070 \mathrm{~nm}$ is not scattered significantly in unreinforced polyamide [19], scattering is neglected in the calculation. Due to the very high feed rate and the low thermal conductivity of plastics, temperature gradients in feed direction are negligible small. Hence, the welding process is modeled as a two-dimensional representation of the cross section, in order to save computation cost and time.

Since the cross section is symmetric, only a half model of the welding process is set up. In previous studies it is shown, that only small deviations are obtained, using these simplification [20]. The time sequence of one scan repetition is modeled as two periods. In the heating period at which the laser irradiates the modeled geometry, the volumetric heat is applied to the plastics. The remaining time of each scan repetition is modeled as the cooling period. In this work, the heat input is approximated to be simultaneous and continuous. In order to carry out this simplification appropriately, a constant heat is calculated using Eq. (2). This equation is obtained, by integrating the time dependent term of Eq. (1) for the duration of one scan repetition and multiplying it with the scan frequency, as deduced in [21].

$\dot{Q}=\frac{8 \cdot \alpha \cdot P}{\pi \cdot d^{2}} \cdot e^{\left(-\alpha \cdot z-8 \cdot \frac{x^{2}}{d^{2}}\right)} \cdot f \cdot \int_{0}^{\frac{1}{f}} e^{-8 \cdot \frac{\left(y_{0}-v_{y} \cdot t\right)^{2}}{d^{2}}} \cdot d t$

In order to ensure a high accuracy, very small finite elements with $10 \mu \mathrm{m}$ height and width are used. The absorption coefficient is influencing the local heat distribution decisively as can be seen in Eq. (1). In order to obtain accurate results in the process simulation, the optical properties of the polymers need to be measured precisely.

\subsection{Evaluation of optical properties}

The absorption coefficient of low scattering polymers is typically evaluated by measuring the normal hemispherical transmittance $\left(\tau_{M}\right)$ and the reflectance $\left(R_{M}\right)$, as also shown by Chen et al. [22] and Kreimeier [23]. Fig. 6 shows these values for an exemplary polyamide 6 sample.

Spectrometers with integration spheres are used in this work. The equipment is described in Honnerova et al. [24]. Beforehand the samples are dried for four hours at a temperature of $80^{\circ} \mathrm{C}$ in order to meet the same conditions as for welding.

The absorption coefficient for the laser wavelength is calculated using the Eqs. (3) and (4). By this, only two surface reflections are taken into account, which seems to be an adequate simplification, as mentioned by Frick [25]. Scattering is not taken into account.

$\tau_{M}(\lambda)=\left(1-R_{1}(\lambda)\right)^{2} \cdot e^{-\alpha \cdot L}$

$R_{M}(\lambda)=R_{1}(\lambda) \cdot\left(1+e^{-2 \cdot \alpha \cdot L}\right)$

Here, $\tau_{M}$ is the measured transmittance, $R_{M}$ the measured reflectance, $R_{1}$ the single-side reflectance, $\lambda$ the wavelength and $L$ the sample thickness. In these equations, the reflection of light on top side

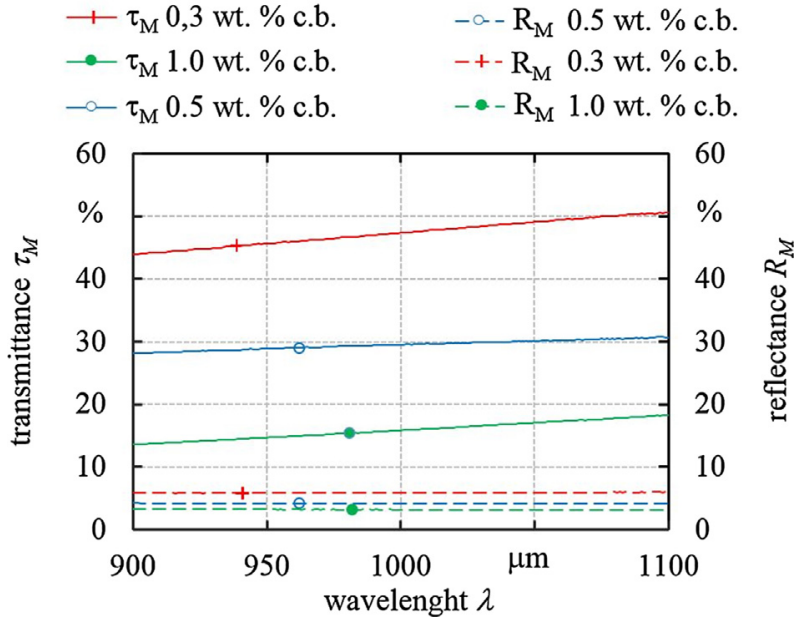

Fig. 6. Spectral transmittance and reflectance of polyamide 6 samples with a thickness of $\mathrm{t}=25 \mu \mathrm{m}$ and various carbon black contents.

and the bottom side is taken into account as well as the exponential attenuation by absorption. The parameter $R_{1}$ and $\alpha$ are unknown and calculated iteratively by solving the Eqs. (3) and (4) in Matlab. The absorption coefficient of the $1 \mathrm{~mm}$ thick semi-transparent polymer is found to be $0.101 / \mathrm{mm}$ for the laser wavelength $(\lambda=1070 \mathrm{~nm})$, whereas the single-side reflectance is $R_{1}=4.6 \%$.

A reduction of the sample thickness is needed for the transmission measurement on carbon black filled polymers. Therefore, the samples are embedded in an epoxy resin. Afterwards, thin-cuts with varying thicknesses from $7 \ldots 50 \mu \mathrm{m}$ are prepared by using a rotary microtome. It is found, that the resulting thickness influences the measured data for transmission and reflection significantly. In order to be aware of the resulting thicknesses, the sheet thicknesses of the thin-cuts are measured, using a laser scanning microscope. The predefined sample thicknesses in the slicing process are corresponding to the resulting thickness of the sample. The deviation between predefined and resulting thicknesses is found to be less than $1.5 \mu \mathrm{m}$. The size of the thin-cuts was $10 \mathrm{~mm} \times 10 \mathrm{~mm}$ to fully cover the entrance port in the spectrometer measurement. Since the thin-cuts were not self-standing, especially those with the tiny thicknesses, they are stuck to a scotch tape during cutting. The scotch tape is made of polypropylene and has a thickness of $45 \mu \mathrm{m}$. As the absorbance is found to be negligible small, the scotch tape is also sticking on the samples during the measurements.

The absorption coefficient of the polymers containing carbon black are shown in Fig. 7. For each carbon black content, thincuts with several different thicknesses were prepared. The data points have comparatively high scatter, but the different carbon black contents can be well distinguished. The absorption coefficients calculated for each thin-cut are averaged to obtain one value for each carbon black content. The detected absorption coefficients are ascending (201/mm, $431 / \mathrm{mm}$ and $941 / \mathrm{mm}$ ) according to the increasing carbon black contents $0.3 \mathrm{wt} \%, 0.5 \mathrm{wt} \%$ and $1 \mathrm{wt} \%$. The averaged single-side reflectance are $4.1 \%, 3.8 \%$ and $3.9 \%$. The single-side reflectance is very close to the calculated reflectance using Fresnel's law and does not change significantly for the various carbon black contents. Measurements on multiple thin-cut thicknesses increase the measurement precision significantly.

The transmittance is also measured on samples with a carbon black content of $1.5 \mathrm{wt} \%$. Here, the transmittance is even for sample thicknesses of $5 \mu \mathrm{m}$ too low. This shows the limitation of the measurement procedure. 
+0.3 wt. \% c.b. 0.5 wt. \% c.b. $\quad 1.0$ wt. \% c.b. ---- average values

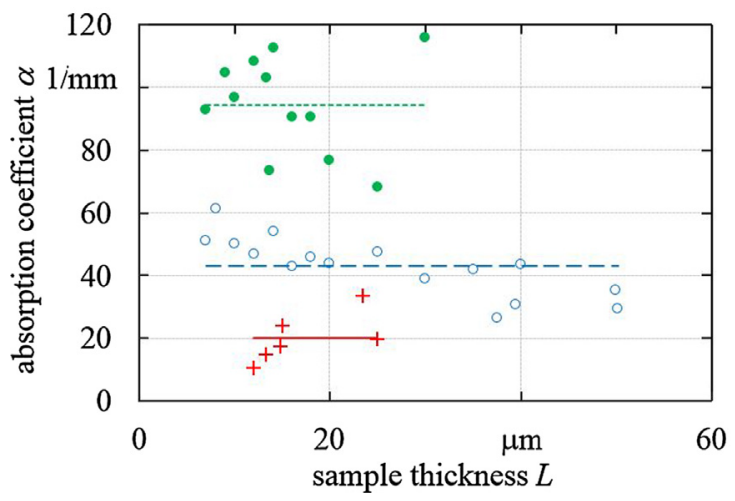

Fig. 7. Determined absorption coefficients of thin-cuts with different thicknesses prepared from polymers with various carbon black contents.

\section{Comparison between simulation and experiment}

The assignment of the measured temperature signal and its location in the weld seam is analyzed experimentally by performing welding experiments with different process parameter settings. Seven welds are performed for each setting. The temperature is measured by using the scanner-integrated pyrometer as well as by using an infrared camera (see Fig. 5). The weld seam geometry is found by analyzing thin-cuts of the weld seams, since the molten area is visible by using polarized light in microscopy. The weld seam geometry determined in the welding experiments is compared to the computed isotherms of the melting temperature $\left(228.3^{\circ} \mathrm{C}\right)$ determined by DSC-analysis, as mentioned by Frick [25] and Kreimeier [23]. Afterwards, the temporal course of the temperature signal $\mathrm{T}_{(\mathrm{y}=0)}$ is compared to the computed mean temperatures in the joining zone.

\subsection{Weld seam geometry}

Fig. 8 shows the weld seam geometries of welds with different carbon black contents (top, middle, bottom). Welds with 30 scan repetitions are in the left half and the ones with 50 scan repetitions on the right. The computed isotherms at $228.3^{\circ} \mathrm{C}$ are displayed in both as well as the weld seam geometry of three representative welds. The initial process parameter setting is used (see Table 1). The changed parameters are noted at each figure.

In general, a good match is found between the measured weld seam geometry and the computed isotherms of the melting temperature. The experimentally determined weld seam depths in the lower polymer are reproduced very precisely by the calculated isotherms, whereas the calculated weld depth in the upper polymer is too large. This effect is seen for 50 scan repetitions clearly, but not for 30 scan repetitions, by comparing left and right column in Fig. 8.

The weld seam depth in the lower polymer is decreasing with increasing carbon black content. This is expected, since the absorption is more intensively concentrated on the surface of the lower polymer with increasing carbon black, whereby material very close to the surface is predominantly heated. In both, the experiment and the simulation, the weld seam depths in the upper polymer are always smaller than in the lower polymer for the welds with $0.3 \mathrm{wt} \%$ c.b. and $0.5 \mathrm{wt} \%$ c.b. In the simulation, this constitution is reversed for the weld with $1.0 \mathrm{wt} \%$ c.b. Here, the weld seam depth in the upper polymer is bigger than in the lower polymer, which is contrary to the experiment.
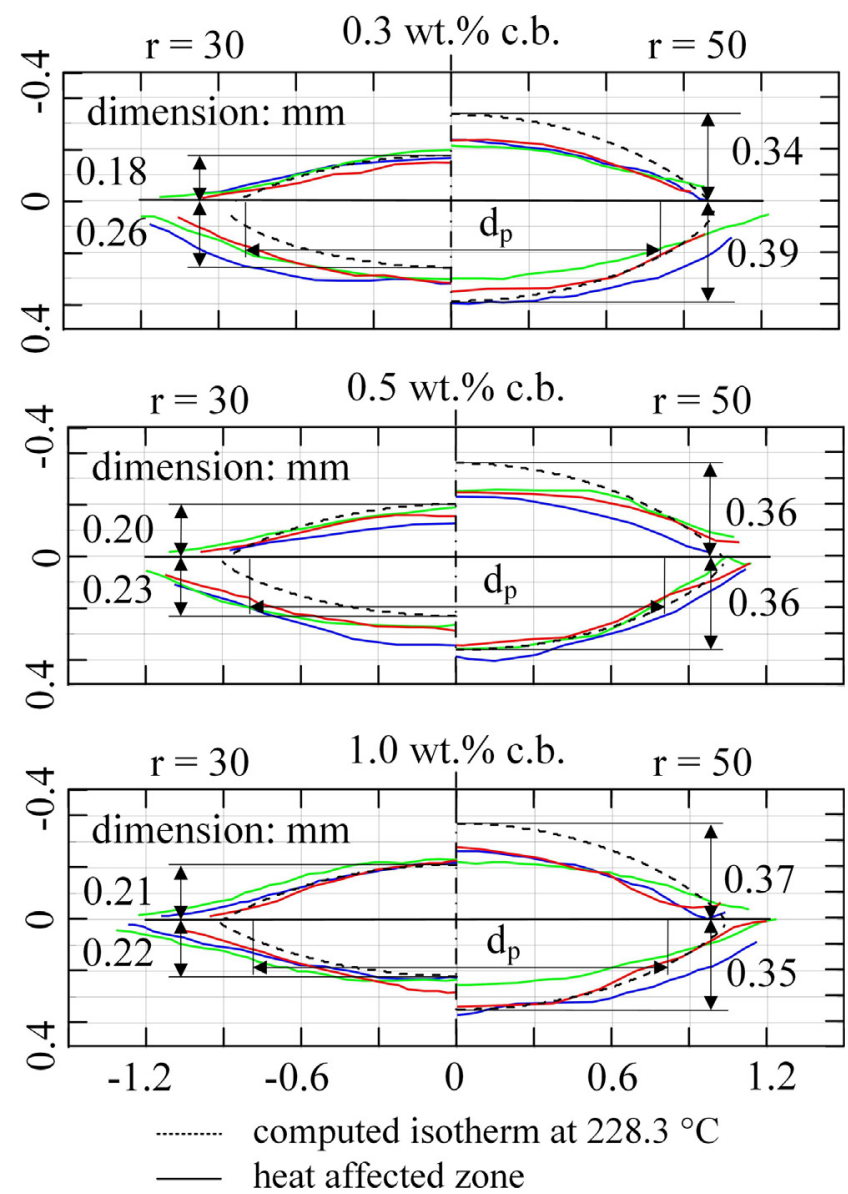

Fig. 8. Measured weld seam geometries of three thin-cuts of welds with 30 and 50 scan repetitions (left and right column) and the computed isotherms of the melting temperature for the welding experiments with different carbon black contents in the lower polymer: 0.3 wt\% c.b. (top), 0.5 wt\% c.b. (middle), $1.0 \mathrm{wt} \%$ c.b. (bottom).

Fig. 9 shows the effect of ascending laser power on the weld seam geometry. The weld seam depths in both polymers is increasing with increasing laser power. However, the weld seam depths in both polymers are nearly identic for each welding setting in the simulation. Again, a good match is found between simulation and experiment, especially in the lower polymer, whereas a difference is seen in the upper polymer.

Finally, the effect of a change in the laser beam diameter is shown in Fig. 10. By using a smaller laser beam diameter, the laser energy is more concentrated to the optical axis, which leads to bigger weld seam depths. This is seen in the simulation and the experiment.

However, there are deviations between the computed and the measured weld seam geometry. At first, the contact situation is assumed to be ideal in the computation, whereby heat transfer into the upper polymer might be higher in the simulation compared to the experiment. Nevertheless, this seems to be an appropriate approach, since thermoplastics are showing a significant thermal expansion, which in general leads to a good contact situation. Also, the dependence of the heat capacity on the heating rates is not taken into account in the simulation, since the measurement of the heat capacity is done at a heating rate of $20 \mathrm{~K} / \mathrm{min}$, which is present in a standardized DSC measurement procedure. Both effects might lead to a bigger weld depth in the upper polymer for the computational results, as reported in [23]. On the experimental side, the weld seam geometries are measured by visual inspection of the images obtained in microscopy. Here, the transi- 

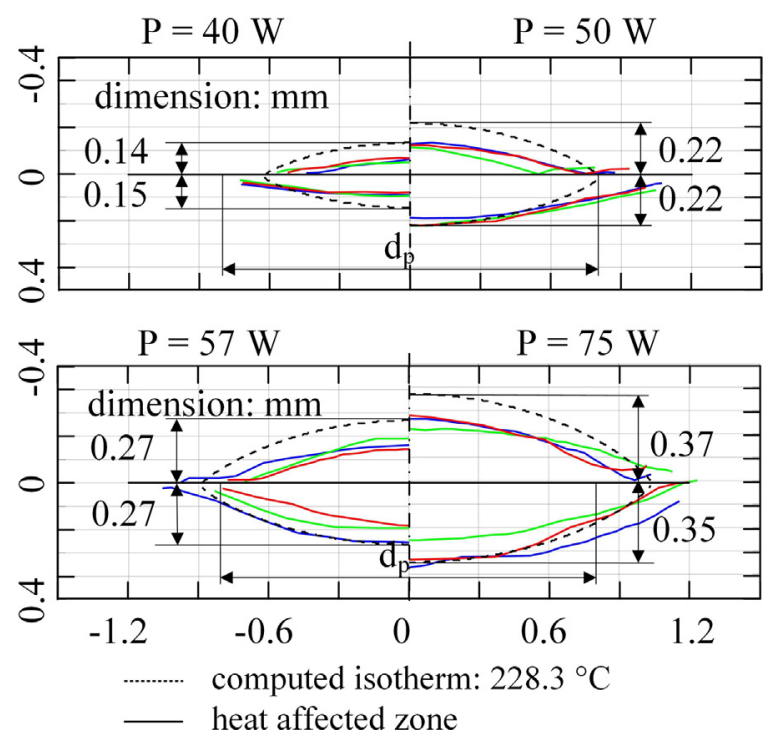

Fig. 9. Measured weld seam geometries of three thin-cuts of welds produced with different laser power and the computed isotherms of the melting temperature.

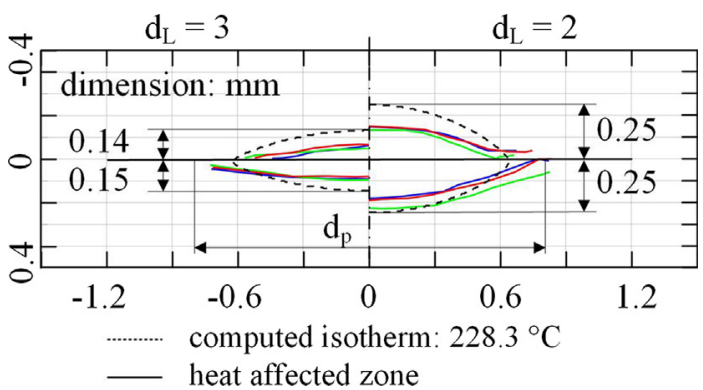

Fig. 10. Measured weld seam geometries of three thin-cuts of welds produced with laser beam diameters of $\mathrm{d}=3 \mathrm{~mm}$ (left) and $\mathrm{d}=2 \mathrm{~mm}$ (right) compared with the computed isotherms of the melting temperature.

tion between melted and not-melted zones is recognizable, but in final consequence also an error of several hundredth of a millimeter are expectable.

It is to state, that the weld seam geometries are reproduced with a high accuracy by the simulation, especially by taking all restrictions into account. Hence, the simulation model is capable to calculate the temperatures in the weld seam accurately.

\subsection{Temperature course}

As the pyrometer yields a discrete temperature signal, the computed temperature field needs to be averaged as well, in order to compare the measured and the computed temperature courses. By considering the spectral sensitivity ranges of the pyrometer and the infrared camera, it seems to be useful to distinguish between heat radiation in the short wave infrared (SWIR) and in the long wave infrared (LWIR). The pyrometer is sensitive for heat radiation in the SWIR, whereas the infrared camera detects heat radiation in the LWIR.

Since the upper polymer strongly filters the heat radiation above approximately $\lambda=2.3 \mu \mathrm{m}$ [1], it is expected, that the temperature signal based on the LWIR heat radiation corresponds to the surface temperature of the upper polymer. Hence, the infrared camera predominantly measures the temperature of the top surface.

Fig. 11 shows the diameter of the detection spot of the pyrometer and the area of interest (AOI) of the infrared camera (left) as

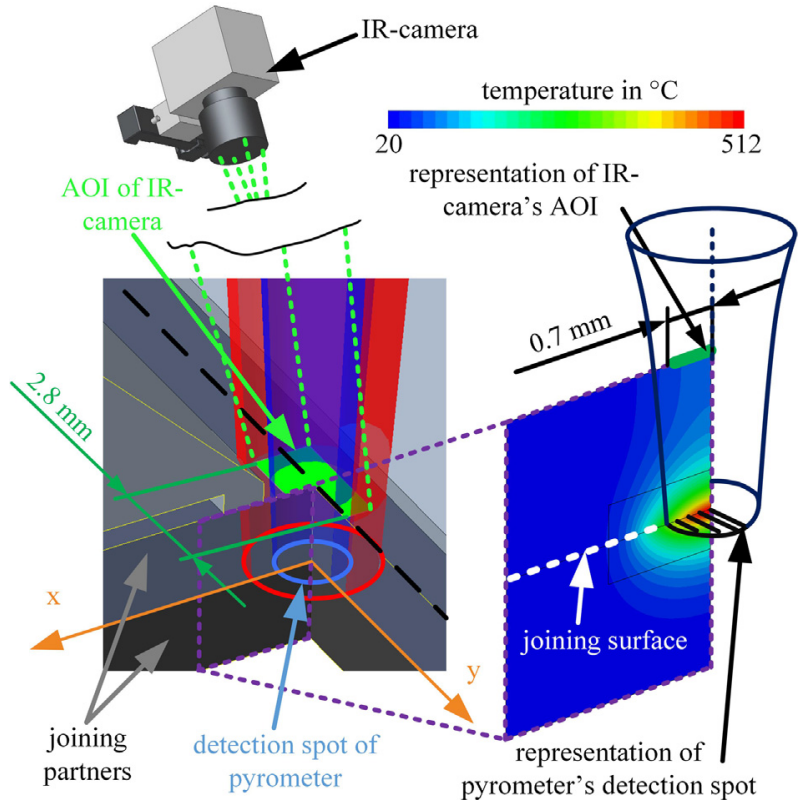

Fig.11. Detection spot of the pyrometer and area-of-interest (AOI) of the infrared camera (left) as well as the computed temperatures in the cross section together with the representation of the pyrometer's detection spot in the simulation (right).

well as the computed temperature field for the weld with the initial process parameter setting, listed in Table 1.

The upper polymer is semi-transparent for heat radiation in the SWIR range, whereby the SWIR radiation is spectrally filtered by absorption. According to the computed temperature field it is expected, that the maximum power of the heat radiation will be emitted from the joining interface. This assumption will be verified in chapter 7. In first proximity, it seems to be an appropriate assumption to calculate a spatially averaged temperature in the joining zone, in order to compare it with the measured temperature signal of the pyrometer. For the averaging of the temperature in the detection spot, it is assumed that there is no temperature gradient in feed direction.

Fig. 12 shows the measured temperature signals from the pyrometer and the infrared camera, compared with the computed mean temperature for welds with different process parameter settings. In the beginning, the computed temperature rises steeply. The temperature-increase reduces steadily with further scan repetitions. This is expected, since a constant laser power is used for each welding configuration. The temperature threshold of $\mathrm{T}=207^{\circ} \mathrm{C}$ is reached after several scan repetitions.

The measured temperature signal $\mathrm{T}_{(\mathrm{y}=0)}$ is shifted to higher temperatures by increasing the carbon black content in the lower polymer. This is also seen in the computed temperature courses (see Fig. 12 top left). Nearly the same progression is seen in simulation and experiment. The computed data is quite similar to the measured temperature signal at a carbon black content of $1.0 \mathrm{wt}$ $\%$, whereas small deviations are seen for the lower carbon black contents (see Fig. 12 top left). The biggest deviation is given for the weld with 0.3 wt\% c.b. The change in carbon black content leads to a significant change in the absorption and thus to a change in the optical penetration depth, as reported in Section 4.2. Hence, the measurement and the simulation shows that an increase of the lower polymer's carbon black content leads to higher temperatures in the joining area.

The carbon black content of the lower polymer is $1.0 \mathrm{wt} \%$ for the subsequent welding experiments, at which the laser power and the laser beam diameter are changed (see Fig. 12 top/right and bottom/left). Here, the progression of the measured and computed 

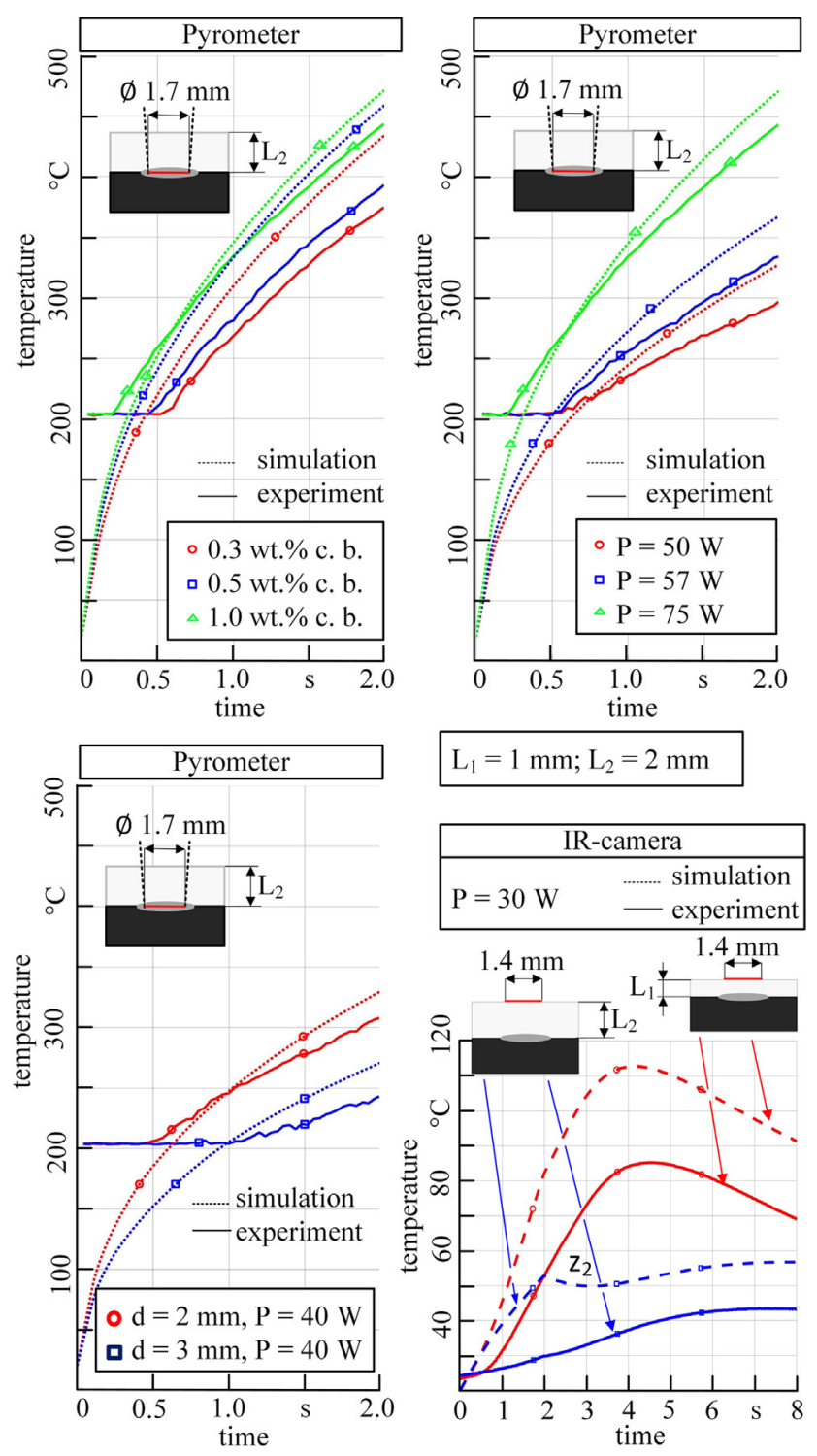

Fig. 12. Pyrometer's temperature signal $T_{(y=0)}$ in comparison with the computed mean temperature $\mathrm{T}_{\text {mean }}$ in the detection spot, located in the joining area: variation of carbon black content in lower polymer (top left), laser power (top right), and laser beam diameter (bottom left); temperature of IR-camera in comparison with simulation results (bottom right).

temperature courses are also in a good match. An increase in temperature is expected for increasing the laser power and for using a smaller laser beam diameter, which is seen in both, the experiment and the simulation.

Fig. 12 (bottom right) shows the measured temperature course and the computed mean temperature in the AOI of the infrared camera for welds with different sheet thicknesses of the upper polymer $\left(\mathrm{L}_{1}=1 \mathrm{~mm}, \mathrm{~L}_{2}=2 \mathrm{~mm}\right)$. For the infrared camera measurement, the emissivity coefficient is set to $\epsilon=0.96$. The computed and the measured temperature courses are showing nearly the same progression. The maximum temperature is reached a few seconds after the laser is switched off. This is caused by the heat conduction from the joining zone. With increasing sheet thickness, the maximum temperature is reached later, caused by the increased distance between the joining area and the upper surface, as also reported by Polster et al. [26] and Martan et al. [3].

The temperature drop after switching the laser off at $t=2 \mathrm{~s}$ is more significantly seen in the temperature course of the weld with
$\mathrm{L}_{2}=2 \mathrm{~mm}$ sheet thickness than it is with $\mathrm{L}_{1}=1 \mathrm{~mm}$. On the top surface, the temperature increases due to the extraordinarily small absorption of laser light, as especially seen on the weld with $\mathrm{L}_{2}=2 \mathrm{~mm}$ sheet thickness. The warming of the top side based on absorption of the laser radiation should be nearly identic for both welds, since it is the same material. However, the measured warming of the top side of the weld with $\mathrm{L}_{1}=1 \mathrm{~mm}$ sheet thickness is much higher compared to the weld with $\mathrm{L}_{2}=2 \mathrm{~mm}$ sheet thickness. This is caused by the heat conduction from the joining interface. Especially the continuous rise of the temperature before and after the laser is switched off confirms the dominance of the heat conduction for the weld with $1 \mathrm{~mm}$ sheet thickness. This is seen more significantly in the simulated temperature courses. In general, low temperatures are seen on the top side compared to the temperatures in the joining interface. The computed temperatures are in both cases higher compared to the measured ones. On the one hand, the implemented absorption coefficient in the upper polymer might be too high, on the other hand convective heat transfer which leads to cooling of the surface, is not implemented, as many assumptions need to be made to estimate the heat transfer coefficient.

\section{Spatial sensitivity of pyrometer lateral to optical axis}

The pyrometer measurement is subject to a certain spatial accuracy. Deviations in the size of the detection spot diameter as well as the coaxial error is affecting the measurement. The spacial accuracy is evaluated on basis of a computed temperature field. However, the pyrometer receives heat radiation on basis of a corresponding temperature. Consequently, hemispherical emission of heat radiation and scattering is not taken into account. Fig. 13 (left) shows the temperature in the joining zone for the weld with initial process parameter setting and the deviation in the temperature course for two coaxial errors (top right) and for two different detection spot diameters (bottom right).

The zones with low temperatures inside the detection spot are quite small (see Fig. 13 bottom left). Thus, the calculated mean temperature is close to the maximum temperature, which is true

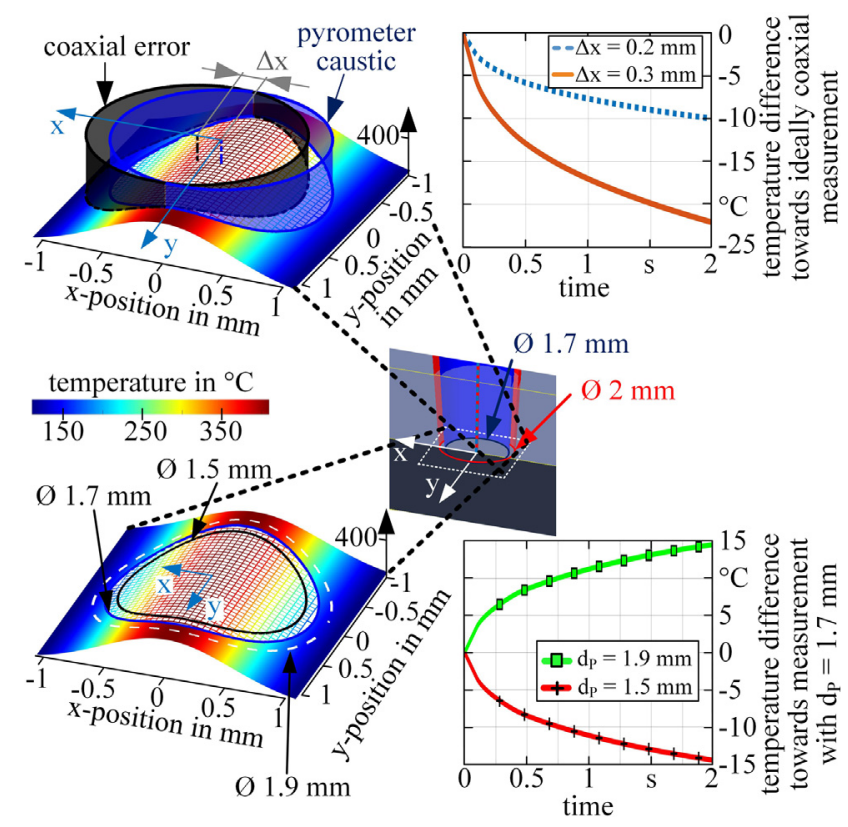

Fig. 13. Temperature field in the joining zone of the weld with initial process parameter setting in combination with two different detection spot diameters (bottom left) and with two coaxial errors (top left) as well as the temperature difference against time by changing the detection spot diameter (left). 
Table 2

Computed maximum, minimum and mean temperature within the detection spot of $\varnothing 1.7 \mathrm{~mm}$ at the end of welding for the welds shown in Fig. 12.

\begin{tabular}{llll}
\hline Changed process parameter & Minimum & Maximum & Mean \\
\hline 0.3 wt\% c.b. & $268.0^{\circ} \mathrm{C}$ & $487.6{ }^{\circ} \mathrm{C}$ & $433.4{ }^{\circ} \mathrm{C}$ \\
0.5 wt\% c.b. & $301.3^{\circ} \mathrm{C}$ & $516.3^{\circ} \mathrm{C}$ & $458.4{ }^{\circ} \mathrm{C}$ \\
1.0 wt\% c.b. & $309.0^{\circ} \mathrm{C}$ & $530.5{ }^{\circ} \mathrm{C}$ & $470.7^{\circ} \mathrm{C}$ \\
$\mathrm{P}=50.6 \mathrm{~W}$ & $219.3^{\circ} \mathrm{C}$ & $367.9{ }^{\circ} \mathrm{C}$ & $327.5^{\circ} \mathrm{C}$ \\
$\mathrm{P}=57.5 \mathrm{~W}$ & $243.4^{\circ} \mathrm{C}$ & $413.3^{\circ} \mathrm{C}$ & $367.4{ }^{\circ} \mathrm{C}$ \\
$\mathrm{P}=75.4 \mathrm{~W}$ & $308.9^{\circ} \mathrm{C}$ & $530.5{ }^{\circ} \mathrm{C}$ & $470.7{ }^{\circ} \mathrm{C}$ \\
d $=2 \mathrm{~mm}$ & $159.5^{\circ} \mathrm{C}$ & $408.8^{\circ} \mathrm{C}$ & $329.3^{\circ} \mathrm{C}$ \\
d $=3 \mathrm{~mm}$ & $183.5^{\circ} \mathrm{C}$ & $302.8^{\circ} \mathrm{C}$ & $270.4{ }^{\circ} \mathrm{C}$ \\
\hline
\end{tabular}

for all welding configurations discussed in this work, as shown in Table 2.

Minimum and maximum temperatures are differing by $119 \ldots 220^{\circ} \mathrm{C}$. The temperature field inside the detection spot is changed for a coaxial error lateral to the feed direction (x). On one side, sections with lower temperatures are inside the detection spot, whereas on the opposite side sections with higher temperatures are included. As the results show, the mean temperature is slightly decreased, by having a coaxial error. However, a coaxial error of $\Delta \mathrm{x}=0.3 \mathrm{~mm}$ leads to a temperature difference lower than $25^{\circ} \mathrm{C}$ (see Fig. 13 top right), which seems to be small sized. A coaxial error in y-direction does not lead to a change in the mean temperature, since the temperatures do not change in feed direction.

Also the determination of the detection spot diameter is subject to a certain accuracy. The mean temperature is increased as far as the detection spot decreases and vice versa. However, a greater and a smaller detection spot diameter by a value of $0.2 \mathrm{~mm}$ only leads to a change in the temperature signal of less than $15^{\circ} \mathrm{C}$ (see Fig. 13 bottom right).

\section{Detected heat radiation along optical axis}

The pyrometer receives heat radiation from both polymers. Therefore, the proportion of the heat radiation is calculated, in order to investigate where the majority is coming from. As the emitted heat radiation is attenuated by absorption, the spectral attenuation needs to be taken into account as well. Fig. 14 shows the measured transmittance and reflectance in the wavelength range of $\lambda=1.5 \ldots 2.5 \mu \mathrm{m}$ of a $1 \mathrm{~mm}$ and a $2 \mathrm{~mm}$ thick sample without any carbon black.

The transmittance is decreasing with increasing wavelength, whereas the reflectance is nearly independent of the wavelength. The absorption coefficient $\alpha(\lambda)$ is calculated using Eqs. (3) and (4) and the measurement data from the $1 \mathrm{~mm}$ thick sample in Fig. 14. In the pyrometers sensitivity range between $1.65 \mu \mathrm{m}$ and $2.1 \mu \mathrm{m}$, the spectral absorption coefficient has values between $\alpha=0.0561 / \mathrm{mm}$ at $\lambda=1.65 \mu \mathrm{m}$ and $\alpha=0.81 / \mathrm{mm}$ at $\lambda=2.051 \mu \mathrm{m}$.

As deduced in [27], the detected heat radiation of a semitransparent sample $(M)$ with a sample thickness $\mathrm{L}$ and a temperature $\mathrm{T}$ at a discrete wavelength $\lambda$ is calculated according to Eq. (5). This equation is based on Planck's law (second multiplicative term).

$$
\begin{aligned}
M\left(\lambda, \Omega_{P}, T, L\right) & =\frac{\Omega_{P}}{2 \cdot \pi} \cdot \int_{z_{u}}^{L} M_{\text {incr }} d z \\
& =\frac{\Omega_{P}}{2 \cdot \pi} \cdot \frac{2 \cdot \pi \cdot c_{0}^{2} \cdot h}{\lambda^{5} \cdot\left[e^{h \cdot \frac{c_{0}}{k \cdot k \cdot T}}-1\right]} \cdot(\underbrace{e^{-\alpha(\lambda) \cdot z_{u}}}_{1}-\underbrace{e^{-\alpha(\lambda) \cdot\left(z_{u}+L\right)}}_{\tau}) ;
\end{aligned}
$$

$z_{u}=0 \mathrm{~mm}$

Here, $d z$ is the differential plate thickness. In the equation it is considered, that only heat radiation inside the solid angle

$$
\begin{array}{ll}
+\tau_{M} \text { L } 1 \mathrm{~mm} & -\infty \tau_{M} \text { L } 2 \mathrm{~mm} \\
-+-\mathrm{R}_{\mathrm{M}} \mathrm{L} 1 \mathrm{~mm} & -\circ \mathrm{R}_{\mathrm{M}} \mathrm{L} 2 \mathrm{~mm}
\end{array}
$$

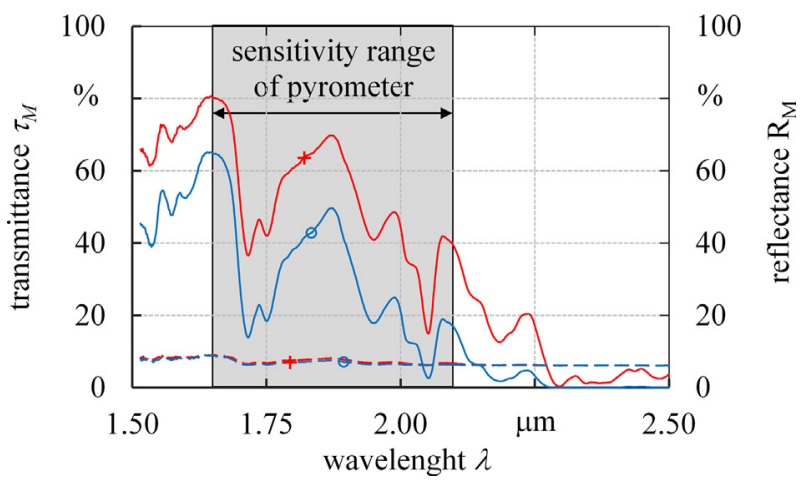

Fig. 14. Measured normal hemispherical transmittance and reflectance for polyamide 6 (Ultramid B3s) samples with thicknesses of $1 \mathrm{~mm}$ and $2 \mathrm{~mm}$.

$\left(\Omega_{P}=1.3 \cdot 10^{-3} \mathrm{sr}\right)$ of the pyrometer caustic is detected (see first multiplicative term). The speed of light $c_{0}$, Planck's constant $h$ and Boltzmann constant $k$ are physical constants. The third multiplicative term of the equation is representing the emission coefficient, since $\epsilon=\mathrm{a}=1-\tau$, according to Kirchoff's law.

The heat radiation passing the surface is calculated by discretizing the polymer with a thickness $L$ into multiple layers, having a thickness $\mathrm{L}_{\text {Layer }}$. Thereby the spatial temperature gradient within the material can be taken into account. Since the pyrometer is sensitive in a spectral range, $M$ has to be calculated for the sensitivity range of the pyrometer (see Eq. (6)).

$$
\begin{aligned}
M_{\text {Layer }}= & \frac{\Omega_{P}}{2 \cdot \pi} \\
& \cdot \int_{\lambda_{L}}^{\lambda_{U}}\left(\frac{2 \cdot \pi \cdot c_{0}^{2} \cdot h}{\lambda^{5} \cdot\left[e^{h \cdot \frac{c_{0}}{k \cdot k T}}-1\right]} \cdot S(\lambda) \cdot\left(1-R_{1}(\lambda)\right) \cdot\left[e^{-\alpha(\lambda) \cdot z_{u}}-e^{-\alpha(\lambda) \cdot\left(z_{u}+L_{\text {Layer }}\right)}\right]\right) d \lambda
\end{aligned}
$$

The pyrometer's spectral sensitivity $S(\lambda)$ within $\lambda_{L}=1.65$ and $\lambda_{\mathrm{L}}=2.1$ is also taken into account. The distance of each layer's upper side to the top surface of the sample is denoted as $z_{\mathrm{u}}$. The total heat radiation of a sample with several layers $(M)$ is the sum of all infinitesimal small portions of emission $\left(M_{\text {Layer }}\right)$. Naturally, all the infinitesimal small portions are partially absorbed, depending on $z_{\mathrm{u}}$ and the spectral absorption coefficients. The surface reflectance $R_{1}(\lambda)$ is also taken into account, since the heat radiation has to leave the sample on the top side. Eq. (6) is used to calculate $\mathrm{M}$ for the upper polymer.

In order to calculate $M$ for the lower polymer, Eq. (6) is transferred to the equation of a black body emitter. Therefore it is assumed, that the emitted heat radiation is completely absorbed in the material itself and only heat radiation emitted from the surface is detected by the pyrometer, assuming $(\alpha(\lambda) \rightarrow \infty)$. By this, the third multiplicative term in Eq. (6) leads to $\epsilon=1$. The filtering by the upper polymer is also taken into account, as well as surface reflection on the top side of the upper polymer.

Fig. 15 (upper left) shows the temperature field of the weld with the initial process parameter setting at the 50th scan repetition. On the upper right, the temperature in the optical axis is shown against coordinate $\mathrm{z}_{\mathrm{u}}$. On the lower left, the course of $\mathrm{M}_{\mathrm{Layer}}$ in the upper polymer is shown, calculated according to Eq. (6).

In the vicinity of the top surface of the upper polymer, the detected emissivity $\mathrm{M}_{\text {Layer }}$ is decreasing towards the joining area. This is based on the increasing attenuation with ascending $z_{\mathrm{u}}$ in combination with a nearly constant temperature. As the tempera- 


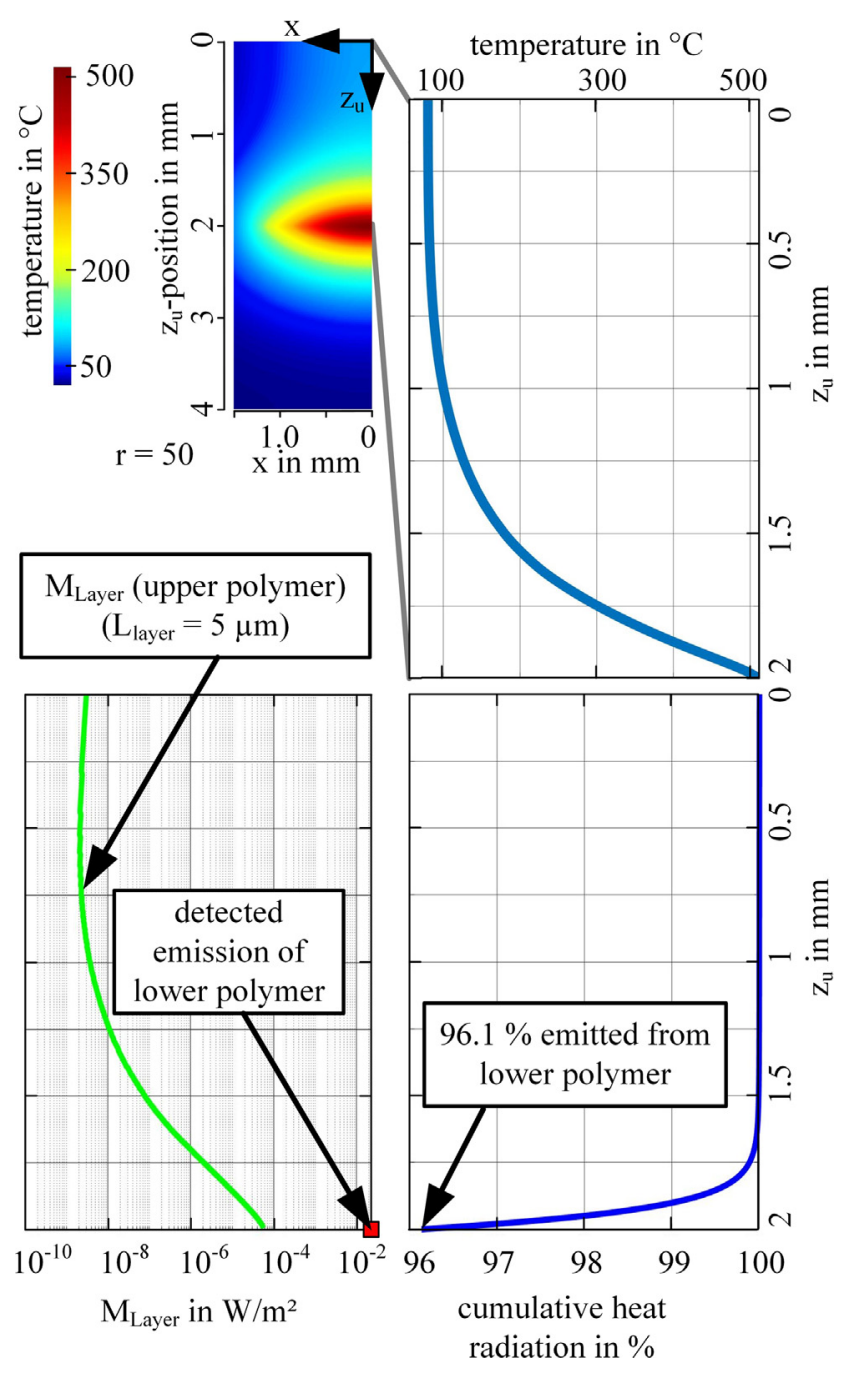

Fig. 15. Temperature field of the weld with the initial process parameter setting at scan repetition 50 (top left) and the temperature along the optical axis (top right), the intensity of emitted heat radiation (bottom left) and the cumulative heat radiation (bottom right).

ture increases significantly, $\mathrm{M}_{\text {Layer }}$ increases, too, since the effect of an increase in temperature is much bigger than the effect of an increased attenuation by filtering. The emitted heat radiation from the joining area is $2.5 \cdot 10^{-2} \mathrm{~W} / \mathrm{m}^{2}$. It is to note, that the data of both polymers in Fig. 15 (lower left) cannot be compared with each other at a certain value of $\mathrm{z}_{\mathrm{u}}$, since $\mathrm{M}_{\text {Layer }}$ of the upper polymer is dependent on the layer thickness. Therefore, the cumulative heat radiation needs to be regarded, which is displayed on the bottom right.

The cumulative heat radiation is plotted against $\mathrm{z}_{\mathrm{u}}$, starting with the detected heat radiation of the lower polymer. Here, $100 \%$ corresponds to the heat radiation of both polymers and is given on the top surface of the upper polymer. It is shown, that $96.1 \%$ of the detected heat radiation is emitted from the lower one. This means, that the detected heat radiation is mainly coming from the joining area. Thus, heat radiation emitted from the upper polymer is negligible small.

\section{Conclusion}

In this work, the core temperature during quasi-simultaneous laser transmission welding is measured on polyamide 6 using a scanner integrated pyrometer. The system is characterized by a coaxial error of less than $0.25 \mathrm{~mm}$ and a detection spot diameter of $\varnothing 1.7 \mathrm{~mm}$. The filtering of the heat radiation in the upper polymer is taken into account by calibrating the pyrometer. The temperature signal is measured during welding experiments by varying the laser power, the laser beam diameter and the carbon black content in the lower polymer. By this, temperatures up to $450{ }^{\circ} \mathrm{C}$ are measured.

In order to compare the experimental results with computed ones, a core temperature is calculated, which is the mean temperature in the joining area inside the detection spot diameter. The absorption coefficients of the lower polymers are measured for the entire set of samples with varying carbon black contents, in order to obtain precise computational results. A measurement procedure is also evaluated, which enables a precise determination of the absorption coefficient for polyamides with carbon black contents up to $1.0 \mathrm{wt} \%$.

It is found, that the temperature signal is in good agreement with the calculated core temperature, also by wide variation of the process parameters. The simulation results are showing that the given errors in coaxial alignment and detection spot diameter are negligibly small for measuring the core temperature. The scattering is neglected in the measurement procedure of the absorption coefficient and also in the computation of the temperature, which is found to be adequate, since the measured and computed temperature are in a good match. More than $90 \%$ of the detected heat radiation is emitted from the joining area, which is found by calculation of the detected heat radiation on basis of the computed temperature. Hence, the heat radiation of the upper polymer is negligible small in the spectral range of an InGaAs-detector.

As shown in this article, the influence of different process parameters on the temperature in the joining zone can be investigated easily, by using the scanner-integrated pyrometer. This offers the possibility for improvement of the process design, the process diagnostic in mass production and also the process control during welding.

\section{Declaration of Competing Interest}

The authors declared that there is no conflict of interest.

\section{Acknowledgement}

The work has been supported by the Bavarian State Ministry of Economy and Media, Energy and Technology (Czech-Bavarian Cross-Border Cooperation Program, INTERREG V-A, EUS 20142020 Objective, TheCoS - Thermoplastic Composite Structures project, No. 103, co-funded by the ERDF and Ministry of Regional Development of the Czech Republic) and the Ministry of Education, Youth and Sports of the Czech Republic (OP RDI program, CENTEM project, No. CZ.1.05/2.1.00/03.0088, co-funded by the ERDF; NPU I program, CENTEM PLUS project No. LO1402).

\section{References}

[1] R. Klein, Laser Welding of Plastics, Wiley-VCH, Weinheim, 2012.

[2] J. Ackermann, Prozesssicherung beim Laserdurchstrahlschweißen thermoplastischer Kunststoffe, Meisenbach, Bamberg, 2010.

[3] J. Martan, J. Tesař, M. Kučera, P. Honnerová, M. Benešová, M. Honner, Analysis of short wavelength infrared radiation during laser welding of plastics, Appl. Opt. 57 (18) (2018) D145.

[4] S. Reinl, Radial welding of polymer parts under closed loop process control: innovative solutions facilitate faster and controlled process, LTJ 12 (3) (2015) $48-52$.

[5] W. Horn, Quasi-simultaneous laser beam welding of polymers in closed loop, in: Society of Plastics Engineers (Ed.), 67th Annual Technical Conference of the Society of Plastics Engineers 2009: ANTEC 2009. Red Hook, NY: Curran, 2009.

[6] V. Wippo, M. Devrient, M. Kern, P. Jaeschke, T. Frick, U. Stute, et al., Evaluation of a Pyrometric-based Temperature Measuring Process for the Laser Transmission Welding, Physics Procedia 39 (2012) 128-136. 
[7] A. Schmailzl, S. Steger, S. Hierl, Process monitoring at laser welding of Thermoplastics: 3D-scanner with integrated pyrometer enables online temperature monitoring at quasi-simultaneous laser transmission welding, LTJ 12 (4) (2015) 34-37.

[8] A. Schmailzl, S. Hierl, M. Schmidt, Gap-bridging During Quasi-simultaneous Laser Transmission Welding, Physics Procedia 83 (2016) 1073-1082.

[9] M. Kučera, J. Martan, A. Franc, Time-resolved temperature measurement during laser marking of stainless steel, Int. J. Heat Mass Transf. 125 (2018) 1061-1068.

[10] D. Moskal, J. Martan, V. Lang, M. Švantner, J. Skála, J. Tesař, Theory and verification of a method for parameter-free laser-flash diffusivity measurement of a single-side object, Int. J. Heat Mass Transf. 102 (2016) 574-584.

[11] C.Y. Wang, P.J. Bates, G. Zak, Optical Properties Characterization of Thermoplastics Used in Laser Transmission Welding: Scattering and Absorbance, Adv. Mater. Res. 97-101 (2010) 3836-3841.

[12] B. Acherjee, A.S. Kuar, S. Mitra, D. Misra, Effect of carbon black on temperature field and weld profile during laser transmission welding of polymers A FEM study, Opt. Laser Technol. 2012 (2012).

[13] C. Hopmann, S. Kreimeier, Modelling the Heating Process in Simultaneous Laser Transmission Welding of Semicrystalline Polymers, Journal of Polymers 2016 (7) (2016) 1-10.

[14] F. Bernhard, Technische Temperaturmessung: Physikalische und messtechnische Grundlagen, Sensoren und Messverfahren, Messfehler und Kalibrierung Handbuch für Forschung und Entwicklung, Anwendungenpraxis und Studium, Springer, Berlin, 2004.

[15] S. Polster, Laserdurchstrahlschweissen transparenter Polymerbauteile [Dissertation], Universität Erlangen-Nürnberg, Bamberg, 2009.

[16] L.S. Mayboudi, Heat transfer modelling and thermal imaging experiments in laser transmission welding of thermoplastics [Dissertation], Queeńs University, Kingston, Ontario, Kanada, 2010.

[17] I.L. Ngo, S. Jeon, C. Byon, Thermal conductivity of transparent and flexible polymers containing fillers: A literature review, Int. J. Heat Mass Transf. 98 (2016) 219-226.
[18] M. Geiger, T. Frick, M. Schmidt, Optical properties of plastics and their role for the modelling of the laser transmission welding process, Prod. Eng. Res. Devel. 3 (1) (2009) 49-55

[19] T. Frick, A. Schkutow, Laser transmission welding of polymers - Irradiation strategies for strongly scattering materials, Procedia CIRP 74 (2018) 538-543.

[20] A. Schmailzl, S. Hierl, Rechenzeitoptimierte Temperaturfeldberechnung beim quasisimultanen Laser-Durchstrahlschweißen, in: C.A.D.F.E.M. GmbH, A.N.S.Y. S. Germany GmbH (Eds.), ANSYS Conference \& 33th CADFEM Users' Meeting ACUM. Grafing bei München, Darmstadt, 2015, pp. 1-15.

[21] A. Schmailzl, S. Hüntelmann, T. Loose, J. Käsbauer, F. Maiwald, S. Hierl, Potentials of the ALE-Method for Modeling Plastics Welding Processes, in Particular for the Quasi-Simultaneous Laser Transmission Welding, in: C. Sommitsch, N. Enzinger, P. Mayr (Eds.), 12th International Seminar "Numerical Analysis of Weldability", TU Graz, Graz, 2018.

[22] M. Chen, G. Zak, P.J. Bates, Effect of carbon black on light transmission in laser welding of thermoplastics, J. Mater. Process. Technol. 211 (1) (2011) 43-47.

[23] S. Kreimeier, Thermische Simulation des Laserdurchstrahlschweißprozesses von teilkristallinen Thermoplasten [Dissertation], Rheinisch Westfälische Technische Hochschule, Aachen, 2017.

[24] P. Honnerová, J. Martan, Z. Veselý, M. Honner, Method for emissivity measurement of semitransparent coatings at ambient temperature, Sci. Rep. 7 (2017) 1386.

[25] T. Frick, Untersuchung der prozessbestimmenden Strahl-StoffWechselwirkungen beim Laserstrahlschweißen von Kunststoffen [Dissertation], Universität Erlangen-Nürnberg, Erlangen, 2007.

[26] S. Polster, J. Zettner, Hochauflösende Wärmeflussanalyse von Laserprozessen und Thermografie in der Qualitätssicherung, in: M. Geiger, S. Polster (Eds.), Laser in der Elektronikproduktion \& Feinwerktechnik: Tagungsband des 9. Erlanger Seminars LEF 2006, Erlangen, 7. - 8. März 2006. Bamberg: Meisenbach, 2006, pp. 27-35.

[27] D.P. DeWitt, G.D. Nutter, Theory and Practice of Radiation Thermometry, Wiley, New York, 1988 